\title{
Instituições, mudanças e estabilidade na pesquisa agropecuária: uma análise do caso brasileiro
}

\author{
Karine Daiane Zingler ${ }^{1}$ \\ Leonardo Xavier da Silva² \\ Glauco Schultz ${ }^{3}$
}

\begin{abstract}
Resumo
A pesquisa agropecuária tem como uma de suas importantes consequências a alteração de determinadas práticas, formas de produzir e uso de insumos, um processo inerente de mudança direcionada à produção agropecuária. De outro lado, essa mudança pode ser planejada e direcionada por determinados atores, entre eles destaca-se o Estado, na forma da política de pesquisa agropecuária, ou pode ser apenas uma reação às mudanças já introduzidas no ambiente. Para tanto, esse artigo, que se propõe a analisar as mudanças na pesquisa agropecuária no Brasil com enfoque na inserção dos temas de pesquisa considerados inovadores, como produção orgânica e agroecologia no âmbito da Empresa Brasileira de Pesquisa Agropecuária, a Embrapa. Tal objetivo é alcançado a partir de pesquisa bibliográfica com aporte teórico na Nova Economia Institucional, pesquisa no portal da Embrapa em sua base de dados, e a partir de um questionário enviado e respondido por pesquisadores e técnicos da organização. Após, as análises e leituras realizadas percebeu-se que existem ações sendo desenvolvidas em assuntos relacionados à agroecologia e agricultura orgânica e agricultura familiar de forma crescente a partir dos anos 2000, porém, ainda parece ter força e grande representatividade a pesquisa convencional, no âmbito da organização pesquisada.
\end{abstract}

Palavras-chave: Pesquisa Agropecuária; Instituições; Tecnologias; Sustentabilidade.

\begin{abstract}
The agricultural research has as one of its important consequences the alteration of certain practices, forms of producing and use of inputs, an inherent process of change directed to agricultural production. On the other hand, this change can be planned and directed by certain actors, among them stands out the state, in the form of agricultural research policy, or it can be only a reaction to changes already introduced in the environment. To this end, this article, which proposes to analyze the changes in agricultural research in Brazil with a focus on the insertion of innovative research themes, such as organic production and agroecology within the Brazilian agricultural research company, Embrapa. This objective is achieved from bibliographical research with theoretical input in the new institutional economy, research in the portal of Embrapa in its database, and from a questionnaire sent and answered by researchers and technicians of the organization. After, the analyses and readings realized that there are actions being developed in issues related to agroecology and organic farming and family farming in a growing way from the years 2000 , however, still seems to have strength and great Representativeness to conventional research, within the scope of the researched organization.
\end{abstract}

Keywords: Agriculture research, institutions, technologies, sustainability. JEL Q16

\footnotetext{
${ }^{1}$ Doutoranda em Desenvolvimento Rural no Programa de Pós-Graduação em Desenvolvimento Rural (PGDR/UFRGS). Professora na Universidade Estadual do Rio Grande do Sul (UERGS). https://orcid.org/0000-00024603-9037. karine.zingler@gmail.com

${ }^{2}$ Doutor em Economia. Professor do Programa de Pós-Graduação em Desenvolvimento Rural (PPGR) e do Programa de Pós-Graduação em Agronegócios (CEPAN), da Universidade Federal do Rio Grande do Sul (UFRGS). leonardo.xavier@ufrgs.br

${ }^{3}$ Doutor em Agronegócios. Professor do Programa de Pós-Graduação em Desenvolvimento Rural (PPGR) e do Programa de Pós-Graduação em Agronegócios (CEPAN), da Universidade Federal do Rio Grande do Sul (UFRGS). glauco.schultz@ufrgs.br
} 


\section{Introdução}

A economia brasileira desde o princípio da sua ocupação até a atualidade está fortemente centrada na produção primária. Mas, ao longo do tempo, a forma dessa importância da participação da agropecuária na composição das riquezas geradas no país tem se alterado substancialmente. $E$, com isso, também a forma de inserção das políticas do setor público na condução econômica do setor primário tem se alterado. Para tanto, parte-se do pressuposto de que, para entender a conformação atual da importância da agropecuária na economia brasileira, precisa-se entender o contexto histórico de formação das políticas que induziram tais transformações.

Segundo dados do IBGE, em 1947 a agropecuária gerava 21,4\% do total do Valor Adicionado Bruto Total da economia brasileira, ao longo dos anos que sucedem, e quando o processo de industrialização do país é efetivamente colocado em marcha, esse percentual cai sucessivamente, e chega a 5,6\%, em 2014, estabilizando-se em torno de 5 a $7 \%$ desde meados da década de 1990. Porém, quando se verifica a importância da agropecuária, dado seu atual estágio de integração com outros setores, é importante que não se analise apenas a geração de riquezas "dentro da porteira", mas sua vinculação com atividades econômicas que lhe fornecem insumos e também para as quais é fornecedora. E, assim, percebe-se então que a importância da agropecuária na economia brasileira é ainda mais relevante. Segundo dados do CEPEA, em 2018 o PIB do agronegócio 4 brasileiro representou $21,1 \%$ do total. Sendo que a composição é dada por $1 \%$ gerados pela produção de insumos, 5,1\% pela agropecuária propriamente dita, 6,3\% pela indústria e 8,7\% pelos serviços vinculados à produção agroindustrial.

Os dados citados acima demonstram que existe, nos últimos anos, notadamente, uma maior integração da agropecuária com outros setores da economia, tanto com a indústria, que cada vez mais fornece insumos para a produção agropecuária, e também cada vez mais utiliza os produtos agrícolas para serem processados e transformados até chegar ao consumidor final, quanto com o setor de serviços, especialmente no fornecimento de serviços de assistência técnica. Então, essa maior integração da agropecuária com os outros setores da economia parece evidente no caso do Brasil, e esse fenômeno tem sido apontado como uma consequência do

\footnotetext{
${ }^{4}$ A noção de agronegócio aqui não tem a conotação ideológica com a qual muitas vezes é utilizada no Brasil. Mas, refere-se ao conceito teórico conforme definido inicialmente por Davis e Goldberg (1957).
} 
processo de modernização da agricultura induzido pelo Estado a partir das políticas agrícolas. (DELGADO, 2012; GONÇALVES NETO, 1997)

A partir dessas considerações, o presente artigo se propõe a discutir a evolução da pesquisa agropecuária no Brasil, no que diz respeito às pesquisas da Embrapa, e verificar a inserção de temas relacionados à agricultura orgânica. Para tanto, a questão que norteia esse trabalho é: Existe uma mudança no foco das pesquisas agropecuárias no Brasil, conduzidas pela Embrapa, na comparação dos períodos de 1960-1985 e 2000-atual? Em que para se ter uma delimitação mais específica se faz um recorte de análise e comparação entre os período de 196085 e 2000-atual, a escolha do recorte temporal é justificada a partir da distinção realizada por Delgado (2012) que analisa a evolução da agropecuária brasileira, sua relação com outros setores e atuação do Estado em dois períodos denominados pelo autor de "modernização conservadora" (1960-1985) e "economia do agronegócio" (de 2000 aos dias atuais). Em termos metodológicos, para responder o problema, utilizou-se de pesquisas bibliográficas e documentais, em livros, artigos científicos, base de dados e publicações da Embrapa, e documentos oficiais disponíveis em sites eletrônicos, e, também, as respostas à um questionário on-line enviado à pesquisadores e técnicos da Embrapa.

Em sua organização, este artigo conta com esta breve introdução, seguida da seção de fundamentação teórica na qual se traz os elementos teóricos da Nova Economia Institucional, em seguida uma seção de metodologia, a seguir os resultados e discussões da pesquisa a partir da subseção que explora a política de pesquisa agropecuária em perspectiva histórica de modo a destacar a criação e atuação da Embrapa, em seguida uma subseção com a atualidade da pesquisa agropecuária e do Sistema Nacional de Pesquisa Agropecuária e os resultados da pesquisa realizada no portal da Embrapa e questionário on-line com pesquisadores e técnicos da organização, por fim, as considerações finais e referências bibliográficas.

\section{Fundamentação teórica: a Nova Economia Institucional}

A Nova Economia Institucional vem ganhando notoriedade na Ciência Econômica como corrente teórica que rompe com alguns pressupostos da economia neoclássica, e que abre caminho para uma visão interdisciplinar, na medida em que passa a considerar a importância de aspectos históricos, sociológicos, antropológicos e cognitivos nas escolhas individuais e no desempenho econômico. A maior visibilidade dessa corrente teórica se inicia na década de 
1990 com os Prêmios Nobel de Ronald Coase (1991) e Douglass North (1993), depois em 2009 com Oliver Williamson e Elinor Ostrom, e em 2016 com Oliver Hart.

Dentre estes autores optou-se, por nesse artigo, explorar as contribuições de Douglass North para a Nova Economia Institucional, identificada por muitos autores como macroinstitucional, já que sua preocupação central é a análise das instituições no desenvolvimento econômico, dessa forma alinhada com os objetivos desse trabalho. E ainda mais justificada pelo fato de que se pretende aqui abordar a mudança institucional, e o autor da Nova Economia Institucional que melhor tem abordado esse tempo é North.

North (2013) define instituições como "regras do jogo", segundo o autor, todas as atividades humanas geram estruturas que definem estas instituições, entendidas como regras formais, normas informais e as características de como elas são aplicadas. E são as instituições que criam incentivos que moldam as escolhas. Sendo que a origem das instituições e seu cumprimento advêm das crenças dos seres humanos.

\begin{abstract}
A estrutura institucional consiste na estrutura política que especifica a maneira como desenvolvemos e fazemos escolhas coletivas, a estrutura de direitos de propriedade que define os incentivos econômicos formais e a estrutura social - normas e convenções que definem os incentivos informais na economia. Essa estrutura institucional reflete as limitações que o passado impõe ao futuro. (North, 2013, p. 9)
\end{abstract}

Para North (1991), instituições são constrangimentos humanamente inventados que estruturam a interação política, econômica e social. Além disso, o autor enfatiza que o desempenho histórico das economias só pode ser entendido a partir da análise da evolução das instituições e da matriz institucional. São as instituições que fornecem a estrutura de incentivos de uma economia. E conforme mudam as instituições, molda-se também a direção da mudança econômica para o crescimento, estagnação ou declínio. Ou seja, para o autor, a grande distância observada entre os países ricos e pobres está mais ligada às diferentes matrizes institucionais do que em problemas de acesso à tecnologia. Pois, o segredo para atingir o crescimento econômico está na construção de uma matriz institucional propícia para o desenvolvimento econômico, sendo que essa análise só faz sentido se considerarmos que a história importa.

Nesse sentido, o objetivo da contribuição de Douglass North para a Nova Economia Institucional é explicar o desempenho variado de economias ao longo do tempo. E que se mostra de grande importância para a construção desse artigo, uma vez que, como pontuado acima, não é somente o acesso à tecnologia o ponto determinante de desenvolvimento econômico, mas, sim a matriz institucional capaz de gerar as interações e conhecimentos necessários para a 
produção de tecnologias próprias e de acordo com as necessidades locais. É importante salientar que Douglass North coloca grande ênfase no papel da construção do conhecimento como ponto fundamental na busca de eficiência econômica. Como deixa claro no trecho a seguir:

\begin{abstract}
A força motriz do desenvolvimento do ambiente humano tem sido a expansão do estoque de conhecimento, que revolucionou as tecnologias de produção e mostrou o potencial de um mundo de abundância. Mas, igualmente, o desenvolvimento institucional resultante criou estruturas cada vez mais complexas para lidar com os novos problemas que desafiam as sociedades. (North, 2013, p. 8)
\end{abstract}

Ou seja, é o conhecimento o elemento central para a produção de tecnologias que podem gerar crescimento econômico. E à medida que existem evoluções tecnológicas e aprimoramento no conhecimento disponível também vão ocorrendo alterações na sociedade que exigem modificações em estruturas econômicas e sociais. Para North (1990) as instituições surgem e evoluem pela interação dos indivíduos.

Mas, nesse processo de formação da matriz institucional, conforme North (2013) existe a importância fundamental do conjunto de crenças da sociedade que determina as normas informais. De outro lado, "é o processo político que impõe as regras formais do jogo, e, portanto, é a fonte primária do desempenho econômico." (NORTH, 2013, p. 10)

Silva (2014) destaca que a matriz institucional, para Douglass North, é constituída do conjunto de regras formais e informais, sendo que as crenças e aspectos culturais da sociedade são fundamentais para esse entendimento, já que as regras formais seriam cristalizações dessas crenças e da maneira como a sociedade se comporta, e indicando as penalizações para o não cumprimento das regras formais. Nesse ponto, aparece um dos conceitos básicos da Nova Economia Institucional que é enforcement, ou seja, a capacidade de fazer cumprir, que é o que realmente dá a credibilidade à matriz institucional. Outro ponto fundamental da Nova Economia Institucional e que é defendido principalmente por Douglass North é a existência de Path dependence, ou dependência de trajetória, evidenciando que a história importa.

Então, admitindo-se que há path dependence, que existe incerteza, que o mundo é não ergódico, ou seja, há alterações inesperadas ao longo do tempo, e que as instituições se modificam ao longo do tempo pelos processos de interações entre indivíduos, e partindo-se do pressuposto de que eficiência não é algo estático, Douglass North sugere a análise econômica a partir da eficiência adaptativa. (SILVA, 2014; NORTH, 2013) Que está relacionado à: “[...] capacidade de interpretar adequadamente as mudanças no ambiente e, a partir disso, ajustar-se 
às condições mutáveis da realidade, para que seja possível ter um comportamento econômico mais próximo do ótimo." (SILVA, 2014, p. 121)

Além disso, conforme North (2018) o processo de mudança institucional ocorre de forma incremental de modo que elementos do passado continuam induzem muitas vezes a mudança, mas ao mesmo continuam presentes nas percepções que os atores têm sobre determinada realidade. E justamente por isso a mudança ocorre, em geral de forma muito lenta.

A partir desse breve resgate das contribuições de Douglass North se tem os elementos teóricos para analisar uma possível mudança institucional na pesquisa agropecuária brasileira, a partir dos procedimentos metodológicos que são destacados adiante.

\section{Metodologia}

Esse artigo tem o objetivo central de analisar a evolução e mudança no foco das pesquisa agropecuária no Brasil, conduzidas pela Embrapa, na comparação nos períodos de 1960-1985 e 2000-atual. Para tanto, utilizou-se de fontes de dados primário e secundário, em pesquisa bibliográfica, pesquisa documental e aplicação de questionários via on-line com técnicos e pesquisadores da Embrapa e suas percepções sobre a mudança institucional nessa organização.

Então, para responder à questão sobre a mudança institucional na pesquisa agropecuária brasileira, fez-se uma pesquisa bibliográfica a partir de obras, livros, artigos, teses e dissertações que já tenham sido redigidos sobre o assunto, em especial sobre a atuação da Embrapa e seus direcionamentos de pesquisa. Nessa fase, também se utilizou de pesquisa documental a partir de documentos disponíveis no Portal da Embrapa e em meio eletrônico, especialmente sobre a criação e atuação da Embrapa.

Posteriormente, a partir do acesso ao Portal da Embrapa na internet, na seção de soluções tecnológicas pode-se analisar a disponibilização de produtos, serviços, técnicas e demais resultados das pesquisas da organização à sociedade. A partir desse acesso, se procedeu à filtragem dos resultados, nesse caso optou-se por analisar a inserção do tema "Agroecologia e produção orgânica". Pois, o foco do artigo é analisar as alterações de pesquisa, que podem incitar um processo de mudança institucional, e como se destaca adiante na seção sobre atuação histórica da Embrapa, percebe-se que historicamente as ações da organização estão direcionadas à tecnologias que intensificam a produção e a produtividade, nos moldes da Revolução Verde, e que tem suas relações com a sustentabilidade ambiental e social muitas vezes questionadas. Por 
isso, a forma para verificar a mudança institucional na Embrapa adotada nesse artigo é a partir da análise de como temas não convencionais se inserem na agenda de pesquisa, nesse caso o foco é para as pesquisas em produção orgânica e agroecologia.

Portanto, a partir dos dados disponibilizados online pela Embrapa, se fez uma análise de como as pesquisas em torno da agroecologia e produção orgânica tem evoluído na organização, para tanto se verificou quais foram as principais unidades que disponibilizaram tais soluções e o ano de divulgação das mesmas. O retorno dessa pesquisa mostrou que desde sua criação, foram divulgadas 139 soluções tecnológicas para produção orgânica e agroecologia. Essa pesquisa foi realizada durante o ano de 2018, e acumulou conhecimento em análise comparativa com outra pesquisa realizada em 2017.

Posteriormente, se procedeu à análise dos principais resultados de um questionário enviado aos pesquisadores e técnicos da Embrapa sobre suas percepções em torno da mudança institucional na organização, e inserção de temas não convencionais como pesquisa em agricultura familiar, produção orgânica e agroecologia. Para tanto, elaborou-se um questionário em plataforma online, em 18 perguntas de diferentes formatos, 13 questões de múltipla escolha, 3 em escala likert (de 1 - discordo totalmente à 5 - concordo totalmente) e 2 perguntas abertas que se propunham a captar elementos e percepções mais gerais dos participantes. O link para acesso à pesquisa foi enviado inicialmente à todas as unidades da Embrapa que tinham contato para comunicação externa e/ou "sala de imprensa", requisitando a divulgação nos meios internos de comunicação as unidades para participação de técnicos e pesquisadores, porém na grande maioria dos casos as unidades retornaram ao contato feito por e-mail indicando a necessidade de aprovação do Gabinete da Presidência. Então, em novembro de 2017, a partir de contato via e-mail com Gabinete da Presidência iniciou-se o trâmite para aprovação e divulgação interna da pesquisa, que algumas semanas depois foi aprovado e divulgado internamente via plataforma interna aos pesquisadores. A adesão em termos de respostas foi relativamente baixa, em um total de 75 respostas contabilizadas em janeiro de 2018, mas que foram analisadas nesse artigo e que demonstram sua importância pela sua ampla abrangência.

A seguir, tem-se os resultados da primeira fase da pesquisa em torno de mudanças institucionais da Embrapa, que é análise histórica da atuação da organização, essa etapa é de suma importância a partir da vertente institucionalista, pois a "história importa". Nessa fase se utilizou principalmente de pesquisa bibliográfica, mas também de pesquisa documental. 


\section{Pesquisa agropecuária no Brasil: mudanças ou continuidade?}

4.1 A política de pesquisa agropecuária e a formação do Sistema Nacional de Pesquisa Agropecuária

Conforme Mengel (2015b), o ano de 1964 é um ponto chave para a análise da mudança de comportamento da política pública em relação à agricultura, com foco na modernização e deixando à margem a discussão sobre reforma agrária. $\mathrm{O}$ ano chave para análise da atuação no Estado, de forma mais evidente, nas relações do setor agrícola no Brasil e criação de políticas agrícolas nos moldes da modernização da agricultura e Revolução Verde é 1965 com a implementação do crédito rural a partir do Sistema Nacional de Crédito Rural (SNCR). Após essa ação, as outras políticas foram se estruturando, entre elas a política de pesquisa agropecuária.

Nesse ponto, parece existir um processo de mudança institucional induzido pelo Estado, o qual, a partir das políticas públicas, passa-se a incentivar a integração capitalista da agricultura brasileira, inicialmente a partir da concessão de crédito que favorece o uso de insumos modernos, externos à propriedade, adoção de novas técnicas de produção que visam ao aumento de produtividade, e também incitam a compra de máquinas e equipamentos que tendem a ampliar a capacidade de produção. E que, ao mesmo tempo, geram demanda crescente por bens produzidos pela indústria.

Mas, há de se ressaltar que a história da pesquisa agropecuária é mais antiga. Para Chagas e Ichikawa (2009), o marco institucional da pesquisa agrícola no Brasil é a criação do Jardim Botânico do Rio de Janeiro, em 1808. Mas, os institutos de ensino e pesquisa agrícola só surgiram mai tarde, com destaque para o Imperial Instituto Baiano de Agricultura em 1859, e dos imperiais institutos das províncias do Rio de Janeiro, Pernambuco, Sergipe e Rio Grande do Sul em 1860. E em 1887 foi criado o Instituto Agronômico de Campinas, com foco em estudos em café. (CHAGAS e ICHIKAWA, 2009)

Para Chagas e Ichikawa (2009), o modelo de desenvolvimento de pesquisa agropecuária no Brasil seguiu o exemplo de alguns países como Inglaterra, Estados Unidos, Japão, mas, principalmente da Alemanha, com fonte de recursos majoritariamente públicos. Porém, no caso brasileiro, o foco das pesquisas estava voltado para atender demandas de grandes produtores em culturas de exportação. Isso começa a se modificar com a Revolução de 1930, quando há uma necessidade maior de oferta de alimentos, e, também, como consequência das políticas de 
industrialização e incentivo à urbanização, que fazem com que a demanda de alimentos avance (CHAGAS E ICHIKAWA, 2009).

\begin{abstract}
Durante os primeiros 50 anos do século passado houve a criação lenta e descontínua das estruturas de pesquisa no plano federal. Alterações de denominação e de abrangência ocorreram no período, principalmente do organismo central da pesquisa federal: em 1943 se chamava Serviço Nacional de Pesquisas Agronômicas (SNPA), em 1962 passou a se chamar Departamento de Pesquisa e Experimentação Agropecuária (DPEA), em 1967 foi denominado Escritório de Pesquisa e Experimentação (EPE), e, em 1971, foi chamado de Departamento Nacional de Pesquisa e Experimentação Agropecuária (DNPEA). (CHAGAS e ICHIKAWA, 2009, p. 98)
\end{abstract}

Para Castro (1984), já no relatório da Comissão Mista Brasil Estados Unidos, em 1949, aparecia a concepção modernizante da política de pesquisa agropecuária a ser instaurada no Brasil, o que vai ficando mais evidente em outros planos analisados pela autora, como Plano de Metas, Plano Trienal PED (Plano Estratégico de Desenvolvimento), I e II PND (Plano Nacional de Desenvolvimento). Mas, segundo a autora, é apenas na década de 1970 que a intenção modernizante se torna efetiva no planejamento público, com inserção de estratégias de difusão de máquinas e insumos modernos e do fomento à pesquisa agropecuária no âmbito das universidades, centro estaduais e do órgão responsável na estrutura do Ministério da Agricultura à época o DNPEA (Departamento Nacional de Pesquisa e Experimentação Agropecuária), no âmbito do planejamento nacional como I PND. Mas, na época o planejamento não era acompanhado de diretrizes e instrumentos de implementação, algo que começa a se tornar mais efetivo apenas com a criação da Embrapa em 1972, e sua integração com universidades e organizações de pesquisa estaduais e centros privados, a partir do Sistema Embrapa. (CASTRO, 1984)

Mengel (2015b) corrobora essa visão afirmando que a base de criação do Sistema Nacional de Pesquisa Agropecuária é de 1972, quando o então Ministro da Agricultura Luís Fernando Cirne Lima, instituiu um grupo de trabalho, por meio da portaria no 143 , cujo objetivo era analisar o então Sistema de Pesquisa Agropecuária Brasileiro. Foi então fundado o Sistema Nacional de Pesquisa Agropecuária e a Empresa Brasileira de Pesquisa Agropecuária - EMBRAPA, enquanto sua coordenadora.

Para Mengel (2015a) a Embrapa foi criada como think thank para modernização da agricultura brasileira, muito mais do que uma organização de pesquisa, havia uma institucionalidade própria. O autor sugere que essa nova organização tinha concepção e organização muito diferente dos seus antecessores. Já que as organizações anteriores não 
conseguiam cumprir os objetivos que a Embrapa passou a desempenhar, principalmente em termos de integração com indústria, nos complexos agroindustriais em construção. Por isso, conforme Mengel (2015a, p. 84) a Embrapa "[...] nasce intimamente ligada aos interesses da industrialização da agricultura brasileira." O autor ainda destaca que entre os fundadores da Embrapa havia uma forte identificação com a teoria da modernização, e do papel dessa organização na criação de tecnologias, nos moldes da Revolução Verde, para gerar incrementos de produtividade na agricultura brasileira.

Mengel (2015a) evidencia que desde a criação da Embrapa houve preocupação fundamental com a qualificação dos pesquisadores, e nesse caso chama atenção que a maioria dos dirigentes já naquela época tinha elevado nível de formação, e geralmente com mestrado e/ou doutorado no exterior, predominantemente nos Estados Unidos, demonstrando tais alianças para implementação do programa.

Sobre os objetivos da Embrapa o autor conclui: “[...] compreender como funcionavam os diversos complexos agroindustriais existentes para buscar prever o comportamento dos agentes do complexo, solucionar os problemas deste e, até mesmo, criar novos complexos mais eficientes." (MENGEL, 2015a, p.111) Por isso, o autor destaca que a Embrapa passou a adotar uma perspectiva mais socioeconômica do que propriamente agronômica, para entender os processos sociais e econômicos das mudanças em relação ao rural brasileiro, e integrar suas pesquisas de modo a acompanhar o processo e induzir mudanças.

Para Cabral (2005) a ideia inicial para constituição da pesquisa agropecuária vinculada essencialmente à Embrapa e sua integração com demais centros de pesquisa em agronômica partiu do Ministro da Agricultura na época, Luiz Fernando Cirne Lima, com prioridade para commodities como café, cacau, cana de açúcar e algodão, mas também fomento à produção de grãos, fruticultura e desenvolvimento florestal. A partir de um longo processo de negociação, a Embrapa passou a coordenar o Sistema Nacional de Pesquisa Agropecuária, no qual as organizações estaduais de pesquisa também teriam um papel importante, principalmente dadas as especificidades locais. Mas, em muitos casos houve dificuldade de negociação com Estados. "Na realidade, o modelo adotado com base em um Sistema Cooperativo requeria mudança radical na cultura local, o que obrigou a longas e difíceis negociações com os governos estaduais." (CABRAL, 2005, p. 92)

Resgatando as contribuições de Douglass North, é perceptível nesse ponto o quanto a história do Sistema Nacional de Pesquisa Agropecuária Brasileira tem a formação de uma matriz 
institucional voltada ao desenvolvimento de tecnologias que têm como objetivo central incrementos de produtividade. Ou seja, o conjunto de crenças, ideologia e regras formais e informais que deu origem ao sistema de pesquisa, e a própria Embrapa estiveram vinculados à noção de modernização da agricultura, e adoção de pacotes tecnológicos típicos da Revolução Verde.

Ainda, segundo Cabral (2005), apesar de ter sido criada no governo Médici, a Embrapa recebeu impulso e foi considerada instrumento de desenvolvimento especialmente no governo de Ernesto Geisel (1974-79), sendo que já nos primeiros dias de governo o novo presidente cobrou em reunião com gestores da organização, a importância da mesma como geradora de tecnologia para garantir o abastecimento interno de alimentos.

[...] Alegou, de pronto, algumas preocupações sobre a capacidade da Embrapa em apoiar a autossuficiência de alimentos de consumo popular no país. Foi seco e direto ao tema. Como Chefe da Nação e em um país como o nosso, não admitia a importação de feijão, arroz, trigo, milho e leite. Para ele, a Embrapa só tinha sentido existir se, via pesquisa e a ajuda direta de crédito e assistência técnica, resolvesse o atendimento à demanda de alimentos essenciais à população brasileira. Lançava um desafio à Diretoria da Empresa para que cumprisse metas de auto-suficiência e sustentabilidade na produção desses alimentos. Daria todo apoio, irrestrito e imediato para a consecução desses objetivos. E iria cobrar resultados. Recomendou ações para a produção de pequenos animais de modo especial a criação de suínos, aves, ovinos e caprinos. (Cabral, 2005, p. 109)

Porém, a partir de 1975, terceiro ano de criação da Embrapa, e a partir do qual, pelo planejamento da organização haveria de se "despontar retornos do esforço realizado", a imprensa passou a publicar reportagens sobre a lentidão da Embrapa em dar os efetivos retornos para a sociedade. Foi nesse momento que os gestores debateram a necessidade de alguma alteração de estratégia para garantir a sobrevivência da organização. E a partir do estoque de conhecimento gerado desde as pesquisas do DNPEA/Ministério da Agricultura, decidiu-se formular "sistemas de produção", ou pacotes tecnológicos. Elaborou-se uma metodologia para elaboração de pacotes tecnológicos que passou a nortear as ações da Embrapa, dos serviços de Extensão Rural e de participação dos produtores. E a partir do diagnóstico de que a maioria dos produtores rurais do Brasil não adotava soluções tecnológicas, e isso gerava um baixo de nível de produtividade da agricultura brasileira. (CABRAL, 2005)

A mudança desse quadro exigia que a pesquisa e a assistência técnica passassem a adotar um modelo de difusão de tecnologia mais dinâmico, demandando interação mais sistemática entre pesquisadores, agentes de assistência técnica e produtores. Em outras palavras: a tecnologia devia preencher, basicamente, o requisito de ser útil, ou seja, 
aquela agronomicamente viável e economicamente rentável para o produtor rural. (CABRAL, 2005, p. 114)

A partir das passagens e contribuições dos autores citados nessa seção pode-se perceber que a criação da Embrapa vem acompanhada de uma incipiente mudança institucional, principalmente no que diz respeito à nova institucionalidade de um trabalho de maior interação entre diferentes organizações. Fica clara também a estratégia da Embrapa como criadora e difusora de tecnologias, de "pacotes tecnológicos", sendo por isso o centro organizador da política de pesquisa agropecuária no Brasil, desde sua criação, em 1972. Mas, também, principalmente a partir do depoimento de Cabral (2005) que essa preocupação com a difusão de tecnologias se confunde muito com uma estratégia de sobrevivência da organização. Já que nessa obra o autor ainda aborda como em diferentes momentos a Embrapa teve ameaçada sua manutenção, principalmente frente à concorrência de organizações de pesquisa privadas e estrangeiras.

Mas, parece que essa mudança institucional não é radical, no sentido de que não rompe com o modelo de desenvolvimento do tipo Revolução Verde, que esteve presente desde o início de criação dessa concepção de Sistema Nacional de Pesquisa Agropecuária, o qual foi criado com um objetivo claro de ampliação da inserção da agricultura no processo de industrialização que se coloca em marcha no Brasil. Então, parece haver uma mudança no sentido de inserção de novos temas, e temas não tradicionais, mas não que isso faça os objetivos institucionais se alterarem radicalmente no período de análise, ao contrário, são objetivos e focos de pesquisa diferenciados, e que podem ser considerados por muitos como antagônicos, e que coexistem na mesma estrutura institucional. Isso poderia ser explicado pela ascensão de grupos com visões diferentes de desenvolvimento agropecuário, e também por mudanças nos objetivos e ações governamentais. De toda forma, pela força e amplitude com que a concepção de desenvolvimento do tipo Revolução Verde foi integrada institucionalmente, ela parece ter criado uma dependência de trajetória, path dependence, conforme a referência conceitual, e isso acaba dificultando uma alteração mais radical nos rumos da pesquisa agropecuária brasileira. Pois, como ressaltado anteriormente, se há incerteza forte, há uma tendência a repetir os padrões de comportamento do passado como forma de sobrevivência.

Mas, se essa estratégia prevaleceu durante longo período de tempo, será que haveria a possibilidade de uma mudança nessa concepção de difusão tecnológica, será que houve alguma 
mudança institucional em relação ao período presente? A resposta, talvez não definitiva é o foco da análise da próxima seção.

\subsection{Atualidade da política de pesquisa agropecuária no Brasil}

Conforme Stumpf Junior e Basaldi (2015), a estrutura do Sistema Nacional de Pesquisa Agropecuária é amplo e envolvia à época a Embrapa em suas 46 unidades, as 17 Organizações Estaduais de Pesquisa Agropecuária e cerca de 200 unidades vinculadas aos Institutos Federais de Educação, Ciência e Tecnologia e universidades públicas que tem cursos ligados à área de ciências agrárias.

Uma das organizações mais importantes desse sistema, sendo sua coordenadora, é a Embrapa, seja por sua capilaridade com ações em todas as regiões do país seja por sua diversidade de produtos. Mas, percebe-se que ao longo do tempo essa organização tem aspectos relacionados ao foco de pesquisa sendo modificados, pois conforme Cabral (2005), é no início da década de 1990, durante o governo Collor, que surge o debate, conduzido pelo então empossado Presidente da Diretoria Executiva, Murilo Flores, de que deveria fazer parte das pesquisas da Embrapa noções de desenvolvimento rural, que seria também incumbência da organização prever ações para diminuir o êxodo rural. Sentia-se a necessidade de revisão do modelo agrícola, rever o papel da agricultura, a fim de reduzir o êxodo rural, e descentralização da renda.

Stumpf Junior e Basaldi (2015) argumentam que é justamente no final da década de 1980 e início dos anos 1990 que a questão do desenvolvimento rural passa a ser mais discutida, integrada e também consequência da ascensão do tema da sustentabilidade ambiental, especialmente a partir da Conferência Mundial do Meio Ambiente em 1992, e também dos debates sobre importância socioeconômica da agricultura familiar. É também nessa época que os movimentos sociais estão mais organizados reivindicando políticas para reforma agrária e agricultura familiar.

A pesquisa agropecuária avançou também sua percepção sobre desenvolvimento rural, e isso parece mais evidente no âmbito da Embrapa. Dentre tais modificações, Cabral (2005) cita a criação do Programa de Agricultura Familiar e uma visão ambiental, além de ser incitada maior participação dos funcionários na definição dos rumos da organização, principalmente para execução de seu processo de planejamento, criando o Sistema Embrapa de Planejamento (SEP).

Há de se destacar outra mudança institucional importante ocorrida no âmbito da Embrapa, pois a partir de 1988, com nova Constituição Federal modificam-se os repasses aos 
governos estaduais. Com as receitas mais concentradas na União, os estados passam a reduzir custos e as organizações estaduais de pesquisa agropecuária, dentre tantos órgãos, entram em decadência, debilitando o Sistema Nacional de Pesquisa Agropecuária. Mas, por outro lado, a capacidade de pesquisa agropecuária de universidades, ONGs, cooperativas e fundações de pesquisa se ampliam no período. Com isso, começa-se a repensar o modelo, e ao invés de Empresas Estaduais de Pesquisa, incita-se a participação de Sistemas Estaduais de Pesquisa, principalmente no Centro-Sul, com incremento de importância dos serviços de extensão e assistência técnica realizada por cooperativas, associações e empresas de insumos agrícolas. A partir daí passou-se a instituir a ideia de que a assistência técnica pública seria prioritária para grupos de agricultura familiar e de reforma agrária, os demais grupos de produtores poderiam ser assistidos pela iniciativa privada. (CABRAL, 2005)

Sobre o um redirecionamento da pesquisa agropecuária em favor do desenvolvimento rural, Cabral (2005) cita que um novo direcionamento é dado a partir da eleição de Luiz Inácio Lula da Silva, com a posse de Clayton Campanhola para presidência da Embrapa.

\begin{abstract}
Na sua posse Campanhola afirmava: "Não basta apenas produzir alimentos. É preciso erradicar a fome! Não basta apenas atingir safras recordes, é preciso distribuir renda! Não basta apenas ampliar a produtividade agropecuária, é preciso incorporar os excluídos do campo ao processo de desenvolvimento."

Decididamente, Clayton inicia seu mandato com um pronunciamento marcadamente de conotação social. Deve-se assinalar, entretanto, que seu discurso menciona outras atividades que deveriam merecer atenção da Embrapa, como a "contribuição para o contínuo fortalecimento do agronegócio brasileiro, o aumento das exportações do país, a rastreabilidade para certificação de origem dos produtos".

Defendia a validação de práticas da agricultura orgânica e da agroecologia, prioritariamente junto aos agricultores familiares. Defendia a geração de informações e resultados científicos sobre impactos no meio ambiente e na saúde humana que podem ser causados por plantas e outros organismos transgênicos, que orientem a tomada de decisões quanto ao seu uso adequado na agricultura. (CABRAL, 2005, p.216)
\end{abstract}

Segundo o autor, a partir de então passa a se dar um foco importante em ações para agricultura familiar, produção de alimentos, mas, ao mesmo tempo, não se exclui a agricultura empresarial, e nem o formato tecnológico de difusão de tecnologias de culturas comerciais, ao contrário essas também passam a ser prioritárias.

Essa dualidade que o autor cita sobre a atuação da pesquisa agropecuária parece evidente quando se analisa a estrutura organizacional e publicações relacionadas ao Sistema Nacional de Pesquisa Agropecuária. Estudos que abrangem temas relacionados à agroecologia e agricultura familiar, mas que também estão bem centrados em tecnologias convencionais, agronegócios e fortalecimento das cadeias agroindustriais tradicionais. Mas, destaca-se que essa dualidade é 
também questionada, já que parte relevante da agricultura familiar, especialmente do CentroSul está plenamente integrada às cadeias agroindustriais, e é produtora de commodities.

Esse reforço em tema relacionado ao agronegócio aparece com destaque o texto conhecido das "Sete teses sobre o mundo rural brasileiro", alguns autores ligados à Embrapa, destacam que no contexto atual, a pesquisa agropecuária teria um papel muito importante, principalmente através da Embrapa em sua "vocação" de produzir tecnologias adaptadas às especificidades das diferentes regiões, sobretudo especificidades edafoclimáticas. Mas, sempre seguindo esse modelo da "Revolução Verde" e vinculado ao conjunto de produtores que teriam capacidade de responder economicamente à estímulos e para absorver tais avanços. De modo algum, haveria possibilidade de inserir uma mudança estrutural, mudança ontológica da pesquisa agropecuária como uma nova visão de mundo sobre a agricultura, pois, para Buanain et. al (2013) não há tempo, nem recursos suficientes para tal.

Por outro lado, no documento EMBRAPA (2006) que fornece o "Marco Referencial em Agroecologia", destaca-se importantes mudanças que ocorreram ao longo da criação da Embrapa para a promoção de uma transição agroecológica. Cita-se os trabalhos pioneiros desenvolvidos em meados da década de 1970 para fixação biológica de nitrogênio, e em 1983 a criação do Programa Nacional de Pesquisa em Biologia do Solo. Segundo o documento ainda na década de 1980 houve o fortalecimento da Agroecologia na organização com a criação da Embrapa Meio Ambiente e da Embrapa Agrobiologia. Também houve fortalecimento do tema, no final da década de 1980 e início dos anos 1990 com modificação de status de diferentes unidades que se transformaram em unidades de pesquisa. No final da década de 1990 a Embrapa organiza o I Encontro Nacional de Pesquisa em Agroecologia, e nos anos 2000 a pesquisa em sistemas orgânicos e biológicos é institucionalizada na Embrapa. (EMBRAPA, 2006)

Essas informações foram corroboradas em pesquisa realizada no site da Embrapa. Foi realizada uma busca na página da Embrapa na internet sobre os resultados de produtos, processos e serviços que a organização disponibilizou desde sua criação, sendo que nessa ferramenta de busca há a possibilidade de aplicar filtros sobre diferentes temas aos quais tais produtos e serviços se relacionam. Após a busca inicial, realizada no mês de janeiro de 2018, chegou-se à 139 resultados de produtos/serviços realizados pela Embrapa para o tema "Agroecologia e Agricultura Orgânica".

Em pesquisa no mesmo site, ao modificarmos o filtro para agricultura familiar, que se seria outro tema não convencional à organização criada para atender objetivos da Revolução 
Verde, o número de resultados amplia-se para 673. Ou seja, no Sistema Nacional de Pesquisa Agropecuário, nos produtos e serviços disponibilizados pela Embrapa, as pesquisas que envolvem a agricultura familiar apresentam-se mais difundidas do que aquelas relacionadas à agroecologia e agricultura orgânica. Percebe-se também que os resultados que se relacionam com o tema agricultura familiar apresentam uma grande amplitude, pois se relacionam com vários outros temas, sendo que os produtos e serviços que se relacionam tanto com agricultura familiar quanto com agroecologia e agricultura orgânica somam 120 resultados.

Então para a análise desse artigo optou-se em analisar a evolução das publicações e disponibilização dos serviços relacionados à agroecologia e agricultura orgânica, sendo o universo de análise os 139 resultados citados anteriormente, essa escolha metodológica foi feita para cumprir o objetivo de entender a mudança institucional a partir da inserção desses temas não convencionais no escopo de pesquisa da pesquisa agropecuária no Brasil, vinculada especificamente à Embrapa. Para tanto, no gráfico 1 se tem as informações a respeito da evolução desse tema nos resultados produzidos ao longo do tempo.

Gráfico 1: Evolução de resultados de produtos/serviços da Embrapa relacionados ao tema "Agroecologia e Agricultura Orgânica" - de 1981 a 2018

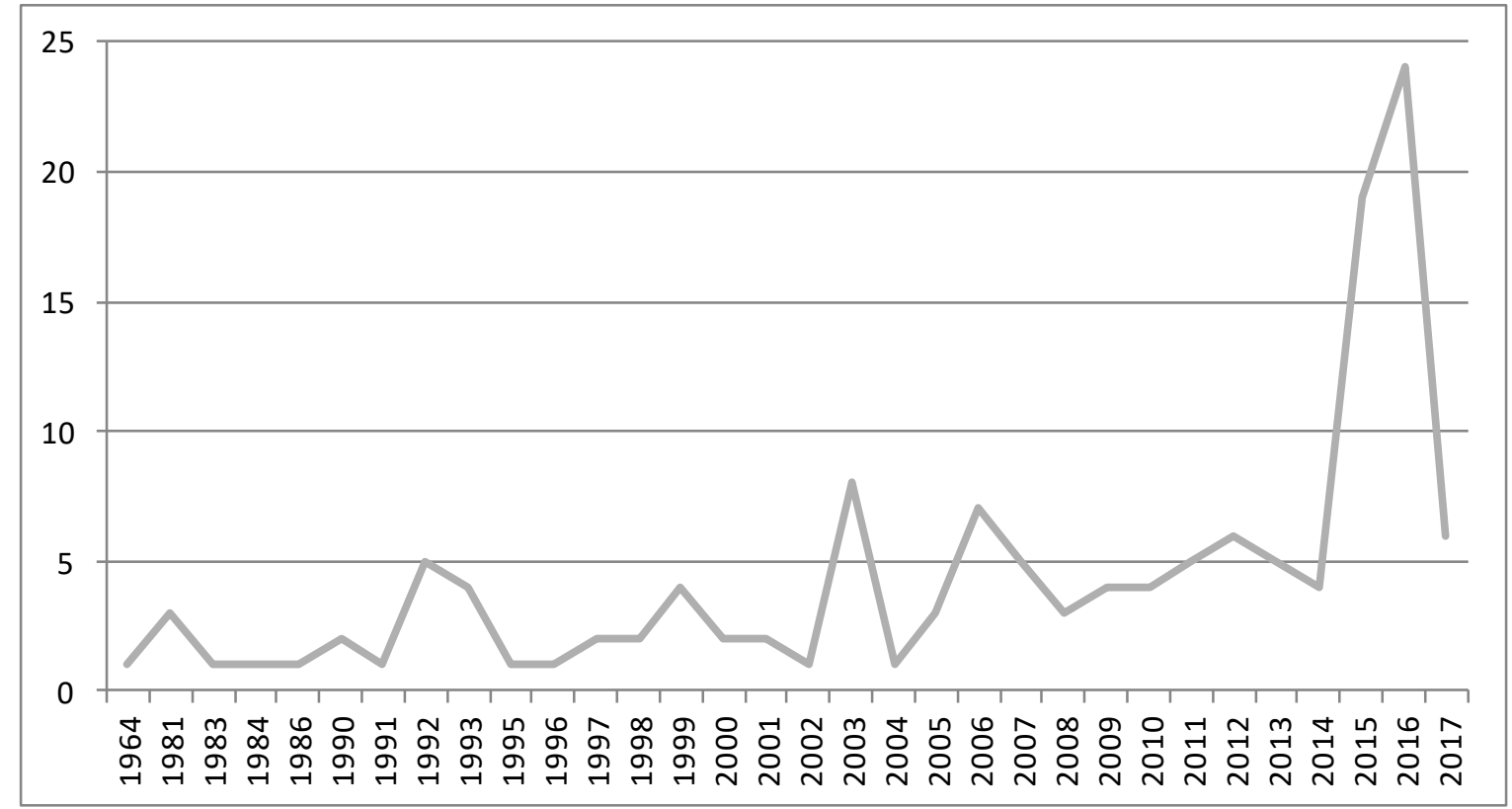

Fonte: Os Autores

Então, sobre os anos de divulgação desses produtos/serviços, nota-se que o tema da agroecologia e agricultura orgânica tem percebido uma maior relevância a partir dos anos 2000. E a evolução de tais publicações corrobora as informações trazidas anteriormente, é no início da 
década de 1980 que aparecem os primeiros trabalhos na área na Embrapa, parece haver um tímido estímulo a partir do início da década de 1990, mas é a partir dos anos 2000 que o assunto recebe maior atenção dentro das pesquisas da organização.

Já, quando se investiga a distribuição dessa produção pelas diferentes unidades da Embrapa, percebe-se que há uma disparidade perceptível entre as unidades, e uma concentração determinadas unidades, conforme dados da pesquisa realizada no Portal da Embrapa, em dois momentos em fevereiro de 2017 e em janeiro de 2018.

A partir dos dados da pesquisa se pode fazer uma análise da inserção do tema agricultura orgânica e agroecologia, e sua evolução entre fevereiro de 2017 e janeiro de 2018 para as diferentes unidades da Embrapa. Destaca-se que das 46 unidades da Embrapa, 25 tem resultados de soluções tecnológicas na área de agricultura orgânica e agroecologia, mas, destaca-se que $50 \%$ do total dos resultados foram realizadas no âmbito da Embrapa Cerrados, isso para os dados de 2018 (70 em um total de 139 registros), em 2017 esse percentual era de 53\% (45 em um total de 85 registros). Ou seja, um pouco mais da metade das unidades da Embrapa tem resultados de soluções tecnológicas em um tema não convencional, que é agricultura orgânica e agroecologia, mas destes, metade está concentrado em uma única unidade. Há de destacar que tais resultados fornecem uma visão inicial sobre um elemento de análise de mudança, mas que merecem um aprofundamento a fim de verificar se realmente outras unidades não tem trabalhos na área, ou se apenas eles não se enquadram nas modalidades registradas como soluções tecnológicas.

Há de se destacar que o total de soluções tecnológicas cadastradas no portal são 2580 , em 13 de janeiro de 2018, nesta data então retornaram 139 resultados para o filtro agricultura orgânica e agroecologia, o que representa o que representa 5,5\%. Apesar da baixa representatividade do tema percebe-se um pequeno incremento em relação à pesquisa realizada em fevereiro de 2017, quando os registros totalizam 2161 resultados, e o retorno para o filtro agricultura orgânica e agroecologia era 85 resultados, o que representava menos de $4 \%$ do total. Ou seja, em um pouco menos de um ano, o número de registros de soluções tecnológicas desenvolvidas pela Embrapa aumentou 19\% (de 2161 para 2580), já o número de resultados em "agricultura orgânica e agroecologia" aumentou em 63\% (de 85 para 139). E como indicado anteriormente houve uma, ainda que tímida, desconcentração, já que no início de 2017, 53\% dos resultados haviam sido realizados pela Embrapa Cerrados e no início de 2018 esse percentual é de $50 \%$. 
No entanto, é preciso fazer uma ressalva importante, essa desconcentração e mesmo aumento de resultados para o filtro indicado pode ser resultado de mera atualização de base de dados. Ou seja, registros mais antigos como da década de 1980, 1990 e início dos anos 2000 que em fevereiro de 2017 não constavam na base de dados, foram inseridos ao longo do ano e em janeiro de 2018 e passaram a constar na análise. Isso parece verdadeiro uma vez que para na pesquisa de 2018 verifica-se, por exemplo, 6 resultados de soluções tecnológicas em "agroecologia e agricultura orgânica" para o ano de 2017 e 24 para o ano de 2016, enquanto que na pesquisa de 2017 os resultados que se tinha era 1 para 2017 e 13 para 2016. Ou seja, parece que os dados estão sendo aos poucos inseridos nesse sistema. Apesar disso, a análise parece pertinente, uma vez que essa é uma das principais plataformas à disposição para avaliar geração de tecnologias que são e poderão ser efetivamente utilizadas pela sociedade, uma vez que outras bases de dados como patentes geradas, e/ou publicações acadêmicas nem sempre serão inseridas como soluções tecnológicas para a sociedade.

Mas, dada essa relativa falta de clareza e lacunas em alguns dados, decidiu-se por avançar na pesquisa a partir da geração de dados de primários com aplicação de questionários junto à pesquisadores e técnicos da organização. Para tanto, decidiu-se por um questionário online, que apesar de suas limitações em termos de captar elementos subjetivos e mesmo de motivar a participação das pessoas, foi a melhor opção em termos de alcance já que a Embrapa possui 46 unidades distribuídas pelas diferentes regiões do país e seria importante a participação do maior número de representantes de unidades nessa pesquisa. Adiante são analisadas algumas respostas e questionamentos que foram julgadas como importantes para a elaboração deste artigo.

O questionário foi constituído de 18 perguntas com questões de múltipla escolha, escala likert e perguntas abertas, e foi enviado via online para as unidades que tinham contato de assessoria de imprensa no Portal da Embrapa, o questionário também foi enviado ao Gabinete da Presidência da Embrapa foi aprovado e enviado para a plataforma dos pesquisadores do Embrapa, segundo contato com assessoria de imprensa da organização. A pesquisa aceitou respostas entre os meses de outubro de 2017 e janeiro de 2018, e contou com 75 participantes provenientes de 26 diferentes unidades da Embrapa, sendo que a unidade que teve mais respondentes foi a Embrapa Cerrados (25,3\% das respostas) e Embrapa Trigo (16\% das respostas). A maioria dos respondentes exerce cargo de pesquisador $(82,7 \%)$ e analista $(14,7 \%)$. 
A maioria dos respondentes trabalho há mais de 15 anos na Embrapa (53,3\%), e 72\% trabalha há mais de 10 anos na organização.

Quando se questionou sobre a facilidade de inserção de temas não convencionais, 41,3\% não vem com facilidade a inserção de pesquisas relacionadas à agricultura familiar e $52 \%$ não vem facilidade a inserção de pesquisas relacionadas à produção orgânica e agroecologia. Em seguida requisitou-se que os respondentes fizessem comentários em relação à estas respostas, ou seja, como percebem a facilidade ou dificuldade de inserir temas relacionados à agricultura orgânica e agroecologia e/ou agricultura familiar no âmbito da Embrapa, nesse caso apenas 51 pessoas responderam, destas 23 destacam que existem ações, mas tais temas são tratados como periféricos ou faltam mais ações, e 20 destacam que existem oportunidades já que os temas estão ligados à missão da Embrapa e /ou se faltar recursos internamente os pesquisadores tem liberdade para buscar parcerias e editais externos.

O que se percebe em geral nas respostas é que existência uma diferença, ressaltada pelos respondentes, no tratamento destes temas em cada uma das unidades. Em nível organizacional há abertura ao tema, mas, não que isso seja algo institucionalizado, pois depende muito dos rumos definidos para a organização em que pode haver mais ou menos recursos e incentivos para os temas, dependendo das decisões de gestão. Além disso, os respondentes destacaram que o tema de agricultura familiar tem maior facilidade de inserção das pesquisas na Embrapa do que "agricultura orgânica e agroecologia".

Posteriormente foi questionado se os respondentes já participaram de pesquisa envolvendo o tema agricultura orgânica e agroecologia, $46,7 \%$ respondeu que sim, destes 53,8\% envolveu-se de 1 a 3 projetos, apenas 4 pessoas responderam que se envolveram em mais de 12 projetos. Dentre as pessoas que responderam que já participaram de projetos na área de agroecologia e produção orgânica, para 31,6\% a principal forma de divulgação do trabalho foi artigo acadêmico, 26,3\% divulgou os resultados da pesquisa a partir da participação de eventos para apresentação de resultados, $15,8 \%$ divulgaram os resultados da pesquisa a partir da publicação de livros.

Sobre os parceiros envolvidos nas pesquisas foram citados: funcionários de outras unidades da Embrapa (30,6\%), Universidades e Institutos de Ensino Superior (28,6\%), empresas e outras organizações privadas (14,3\%), outras organizações públicas de pesquisa situadas no Brasil (12,2\%), somente funcionários de uma unidade da Embrapa $(10,2 \%)$ e organizações de pesquisa ou universidades estrangeiras $(4,1 \%)$. 
Já quando foi questionado aos respondentes se eles percebem a estruturação de um projeto nacional de pesquisa agropecuária em favor de temas relacionados à agricultura familiar e agricultura orgânica e agroecologia, $22,7 \%$ discordam totalmente, por outro lado $4 \%$ concordam totalmente. O que corrobora os resultados da questão seguinte, na qual se questionou se tais temas eram considerados inovadores para a pesquisa no âmbito da Embrapa, e $8 \%$ concordaram totalmente, enquanto $30,7 \%$ discordaram totalmente.

Por fim, com o intuito de se verificar a influência exercida pelo MAPA na Embrapa, e verificar hipótese de enforcement, questionou-se: De uma escala que vai de 1 (discordo totalmente) até 5 (concordo totalmente), existe influência, ou direcionamento do MAPA (Ministério da Agricultura Pecuária e Abastecimento) ou da mudança política no direcionamento das suas pesquisas? As respostas foram: 1 (17,3\%), 2 (18,7\%), 3 (29,3\%), 4 (17,3\%), 5 (17,3\%).

O que se percebe em geral, pelas análises das respostas é que como existem muitas unidades com viés de pesquisa diferenciado, e formas de pensamento em concepções teóricas diferentes dos gestores das unidades, em geral é isso que vai determinar um maior ou menor incentivo à inserção de temas não convencionais. E isso é perceptível à medida que em uma mesma organização que tem uma única missão organizacional, existem unidades que tratam tais temas com mais ou menos prioridade.

Então se percebe que existem elementos latentes de mudanças institucionais na pesquisa agropecuária brasileira, inclusive como necessidade de adaptação ao ambiente que se modifica com ascensão de diferentes grupos políticos no país, o que parece inclusive uma estratégia de sobrevivência. Mas, essas mudanças são sutis, e vinculadas às regras do jogo vigente, pensar em uma "virada" sistêmica com foco exclusivo em agricultura familiar e sustentabilidade, parece algo mais distante, inclusive pelo fato de que, principalmente no Brasil, essas novas regras do jogo não parecem estar totalmente estabelecidas.

\section{Considerações finais}

Este breve estudo teve o objetivo de analisar se temas tidos como não convencionais estão realmente se integrando a pesquisa agropecuária brasileira, para isso utilizou-se do aporte teórico da Nova Economia Institucional, sobretudo as contribuições Douglass North. Para este autor, que estuda processos de mudança institucional e desempenho econômico, a mudança é um processo incremental e dependente historicamente, onde a interação entre os indivíduos 
forma uma estrutura institucional integrada por restrições formais e informais que determinam as escolhas dos atores. A partir dessa visão teórica passou-se à análise específica das pesquisas no âmbito da Embrapa, organização esta que historicamente tem sua formação e atuação vinculada às pesquisas com objetivo no aumento de produção, que não necessariamente exclui, mas, nem sempre inclui cuidados ambientais e sociais. Essa parte da pesquisa foi feita a partir da análise de resultados em banco de dados online da Embrapa e, também, com questionários online que foram enviados às unidades e disponibilizados aos pesquisadores e funcionários dessa organização de pesquisa.

Então, a Nova Economia Institucional tem fornecido um importante referencial teórico para análises das mudanças ocorridas nas relações que envolvem os atores do desenvolvimento rural. Mudanças que permeiam o processo de desenvolvimento da economia brasileira e que influenciam, criam ou inibem diferentes formas de produção agropecuária, muitas vezes induzidas pelo Estado. Dessa forma, a partir da década de 1960, quando se institui a política agrícola com a criação do Sistema Nacional de Crédito Rural, há um processo de mudança institucional importante, em que o Estado passa a induzir de forma ampla a integração da agricultura à estrutura agroindustrial que vinha se formando. Na década de 1990, com a abertura econômica e paulatina mudança no perfil de intervenção do Estado na economia, há outra mudança institucional importante.

Já no que se refere à pesquisa agropecuária, ela está instituída no Brasil há mais de dois séculos, mas, em sua fase inicial esteve concentrada em poucos centros e com ênfase em determinados produtos, realizada de forma desarticulada. Esta se tornou efetivamente uma política de Estado, tornando-se institucionalizada a partir da década de 1970, com a criação da Embrapa, que desde o início esteve muito vinculada à difusão de tecnologias nos moldes da Revolução Verde. Agora passado quase meio século da sua criação analisa-se a diversificação de foco dessa organização que coordena o Sistema Nacional de Pesquisa Agropecuária e é muito vinculada ao direcionamento da política de pesquisa agropecuária no Brasil, de modo a prestar mais atenção nas questões de desenvolvimento rural, sustentabilidade e tecnologias sociais.

Sobre a questão inicial que esse trabalho pretendeu responder: Existe uma mudança no foco das pesquisas agropecuárias no Brasil, conduzidas pela Embrapa, na comparação dos períodos de 1960-1985 e 2000-atual? Parece que sim, mas essas mudanças são sutis, não há, por exemplo, uma virada ou mudança total de foco, mas sim diferentes percepções que são instituídas e coexistem, mesmo que para muitos analistas possam parecem antagônicas. Tal fato 
pode também ser explicado por um processo de dependência de trajetória, ou path dependence ligada à institucionalização do Sistema Nacional de Pesquisa Agropecuária e seus objetivos relacionados à difusão de tecnologias da Revolução Verde e industrialização da agricultura. Mas, isso pode ser justificado pela amplitude e diversidade do Sistema Nacional de Pesquisa Agropecuária e mesmo da Embrapa sua coordenadora. E esses resultados parecem mais evidentes na análise do discurso de Cabral (2005).

Além disso, o fato de que atualmente as pesquisas em torno da agricultura orgânica estejam concentradas em poucos, e uma unidade principal mostra de um lado que o tema vem se inserindo em magnitudes diferentes e que talvez não esteja sendo instituído, mas sim resultado da intenção de atores mais isolados. Mas, de outro lado as unidades também têm diferentes trajetórias e foram implementadas em diferentes horizontes temporais, isso quer dizer que uma unidade pode ter mais publicações em determinado assunto que outra pelo fato de ser mais antiga e de ter equipes consolidadas a mais tempo. Já unidades de criação mais recente justamente podem ter menos resultados por serem mais jovens. $E$ isso parece ainda mais evidente quando se tem um resultado de mais da metade dos pesquisadores entrevistados nessa pesquisa revelam que pesquisas vinculadas à agroecologia e agricultura orgânica não são facilmente inseridas na organização.

O fato é que a pesquisa agropecuária para manter sua estrutura vem integrando esses temas que até a década de 1980 eram pouco debatidos, mas que a partir da sua ascensão, vem ganhando espaço no âmbito da Embrapa, que tradicionalmente trabalhou com tecnologias poupadoras de mão de obra e que são apontadas muitas vezes como geradoras de êxodo rural e problemas sociais e ambientais nas áreas rurais. Mas, ao mesmo tempo, as pesquisas nesse campo não estão excluídas, pois existe uma vinculação histórica de tais temas à estrutura organizacional e ambiente institucional no qual a organização está inserida. E, também, pelo fato de que as regras do jogo, em termos de políticas públicas e direcionamento de recursos ainda não estão totalmente definidas nessa área. Por isso, a fim de que tais constatações sejam mais conclusivas é importante que pesquisas nessas áreas sejam aprofundadas com análises de outros documentos e pesquisas publicadas no âmbito do Sistema Nacional de Pesquisa Agropecuária, em perspectiva histórica.

Nesse sentido, parece que a matriz institucional da pesquisa agropecuária, fruto das escolhas coletivas e que foi formada a partir das crenças da sociedade, na qual se constituíram tais regras do jogo, apresenta um processo lento e incipiente de mudança agregando temas não 
convencionais de estudo. Mas, o movimento de mudança institucional ainda parece não ser mais forte que a dependência da trajetória, uma vez que também se trata de manutenção de estratégias de sobrevivência. Porém, como assinala Douglass North, a mudança institucional é um processo lento e incremental e por isso a continuidade e ampliação do estudo e observação em torno desse tema são fundamentais, também para perceber estratégias de desenvolvimento de longo prazo em nível setorial e nacional.

\section{Referências}

BACHA, Carlos J. C. Economia e Política Agrícola no Brasil. 2 ed. São Paulo: Atlas, 2012.

BCB. Anuário Estatístico do Crédito Rural até 2012. Disponível em: http://www.bcb.gov.br/?RELRURAL2012. Acesso em: 20/02/2018.

BUANAIN, A. M. et al. Sete teses sobre o mundo rural brasileiro. Revista de Política Agrícola. Brasília/DF, Ano XXII, n. 2, p. 105-121, abr./maio/jun. 2013.

CABRAL, J. Irineu. Sol da manhã: memória da Embrapa. Brasília: UNESCO, 2005.

CASTRO, Ana Célia. Ciência e Tecnologia para Agricultura: uma análise dos planos de desenvolvimento. Cadernos Difusão de Tecnologia. Vol. 1. nํ. 1984.

CAVALCANTE, Carolina Miranda. A Economia Institucional e as Três Dimensões das Instituições. Revista de Economia Contemporânea. Vol. 18. nำ3. 2014.

CEPEA. PIB do Agronegócio Brasileiro: dados de 1995 a 2017. Disponível em: http://www.cepea.esalq.usp.br/br/pib-do-agronegocio-brasileiro.aspx. Acesso em: 14/01/2018.

CHAGAS, Priscilla B.; ICHIKAWA, Elisa Y. Redes de C\&T em Institutos Públicos de Pesquisa Brasileiros: o caso do Instituto Agronômico do Paraná (lapar). Revista de Administração Pública. Vol. 43. nำ1. 2009.

DELGADO, G. Do "capital financeiro na agricultura" a economia do agronegócio: mudanças cíclicas em meio século (1965-2012). Porto Alegre: Editora da UFRGS, 2012.

EMPRESA BRASILEIRA DE PESQUISA AGROPECUÁRIA [EMBRAPA]. Marco Referencial em Agroecologia. Brasília: Embrapa Informação Tecnológica, 2006.

EMPRESA BRASILEIRA DE PESQUISA AGROPECUÁRIA [EMBRAPA]. Busca sobre Produtos, Processos e Serviços. Disponível em: https://www.embrapa.br/busca-de-produtos-processos-eservicos?p auth=eoyPX1Un\&p p id=buscaprodutoservico WAR_pcebusca6 1portlet\&p_p life cycle $=1 \& p$ p state $=$ normal $\& p$ p mode $=v i e w \& p$ p col id=column-

$1 \& p$ p col count $=1 \&$ buscaprodutoservico WAR pcebusca6 1portlet javax.portlet.action $=b$ uscarProdutosServicos\& buscaprodutoservico WAR pcebusca6 1portlet delta $=10$. Acesso em: 28/02/2017.

FONSECA, Pedro C. D. Sobre a Intencionalidade da Política Industrializante no Brasil na Década de 1930. In: Revista de Economia Política, São Paulo, jan/mar 2003, n. 89, p.133-148.

FURTADO, Celso. Formação Econômica do Brasil. 17ạ Ed. São Paulo: Companhia Editora Nacional, 1980. 
GONÇALVES NETO, W. Estado e agricultura no Brasil: política agrícola e modernização econômica brasileira 1960-1980. São Paulo: HUCITEC, 1997.

IBGE. Participação do Valor Adicionado Bruto da Agropecuária em relação ao Valor Adicionado Bruto Total. Disponível em:

http://seriesestatisticas.ibge.gov.br/series.aspx?no=12\&op=0\&vcodigo=SCN28\&t=participacaovalor-adicionado-bruto-agropecuariabrem-relacao. Acesso em: 17/12/2016.

MENGEL, Aléx Alexandre. Modernização da Agricultura no Brasil: A Empresa Brasileira de Pesquisa Agropecuária - Embrapa. Tese de Doutorado. Rio de Janeiro: Universidade Federal Rural do Rio de Janeiro, Instituto de Ciências Humanas e Sociais. 2015a.

MENGEL, Aléx Alexandre; AQUINO, Silvia Lima de. Modernização da Agricultura e a Criação da Embrapa: transformações na pesquisa agropecuária brasileira. Campo-Território: Revista de Geografia Agrária. Vol. 10. n21. 2015b.

MIELITZ, Carlos A. A política agrícola brasileira sua adequação e sua funcionalidade nos vários momentos do desenvolvimento nacional. In: BONNAL, Philippe; PEREIRA LEITE, Sérgio. Análise Comparada de Políticas Agrícolas - uma agenda em transformação. Rio de Janeiro: Mauad X, 2011.

NORTH, Douglass. La Nueva Economía Institucional. Revista Libertas, 1990.

NORTH, Douglass. Institutions. The Journal of Economic Perspectives, Vol. 5, No. 1 (Winter, 1991), pp. 97-112.

NORTH, Douglass. Entendendo o processo de mudança econômica. Traduzido por: FENDT, Roberto. Clássicos Liberais. Revista Banco de Ideias. n.46. 18p. 2013.

NORTH, Douglass. Instituições, Mudança Institucional e Desempenho Econômico. Trad. MORALES, Alexandre. São Paulo: Três Estrelas, 2018.

SILVA, Leonardo Xavier da. Instituições e Desempenho: interpretações para o entendimento do desenvolvimento rural. In: CONTERATO, Marcelo A.; RADOMSKY, Guilherme F.W.; SCHNEIDER, Sérgio. Pesquisa em Desenvolvimento Rural: aportes teóricos e proposições metodológicas. Volume 1. Porto Alegre: Editora da UFRGS, 2014.

STUMPF JUNIOR, Waldir; BASALDI, Otavio Valentim. Políticas Públicas e pesquisa para o desenvolvimento rural no Brasil. In: GRISA, Cátia; SCHNEIDER, Sérgio (org). Políticas Públicas e Desenvolvimento Rural. Porto Alegre: Editora da UFRGS, 2015.

ZINGLER, Karine D. SILVA; Leonardo X. da; SCHULTZ, Glauco. Política de Pesquisa Agropecuária: processos de mudança institucional no caso brasileiro. Anais de Evento. 55 Congresso da SOBER. Santa Maria-RS, 2017. 